Research Article

\title{
Online learning amid COVID-19 pandemic: Perspectives of Bhutanese students
}

\author{
Norbu Wangdi, Yeshi Dema and Ngawang Chogyel \\ Gongzim Ugyen Dorji Central School, Haa, Bhutan
}

\begin{abstract}
The outbreak of COVID-19 has affected every aspects of human life around the globe. Education is one of the sectors that has been severely affected due to the outbreak of coronavirus. Schools in more than 190 countries got shut down to break the chain of coronavirus. Therefore, this study was aimed to examine the perspectives of Bhutanese students towards online learning amid COVID-19 pandemic. The study employed mixed method to triangulate the data and solidify the findings. A total participants of 200 day scholar students of the school was selected through purposive sampling. Data collection was carried out using survey questionnaire and interview questions and analyzed based on descriptive statistics and thematic analysis. The findings of the study disclosed that the cost of internet in Bhutan is too expensive for students and the teachers were not well-equipped with knowledge and skills to manage online classes. The study also showed that about 70 percent of participants do not have their own personal smartphones/laptops to attain online classes. Thus this study recommend ministry of education to provide workshop for teachers to enhance their digital knowledge and look at the possibilities to reduce the cost of internet for the benefit of our students.
\end{abstract}

Keywords: Online learning, digital knowledge, competent, technology, COVID-19

\section{Introduction}

The COVID-19 pandemic has created largest destruction to the education system across the world. As of August 2020, the pandemic has affected nearly 1.9 billion learners in more than 190 countries. The schools, colleges and other educational institutes were shut down to contain the spread of coronavirus (United Nations, 2020). Bhutan has not been an exception to the destruction as the country went to close the schools across the nation during the month of midMarch 2020 after the first COVID case was detected. The schools, colleges and other institutes across Bhutan were closed as government imposed strict lockdown to break the chain of coronavirus. As a prompt response to curb the spread of coronavirus, Royal government of Bhutan issued official directives to close the schools and continue teaching through various online methods (Kado et al., 2020).

In response to the call of the nation, Ministry of Education has directed the schools across the country to conduct teaching and learning through online platforms. Schools in Bhutan conducted online education through google classrooms. WeChat, WhatsApp and Facebook messenger were some of the social media applications used by the schools for the online classes. Further, to keep the students engaged during the lockdown, the ministry of education initiated the video recording of the lessons and was broadcasted through the national television channel. The official Facebook page of Prime Minister (PMO) stated that as we continue to monitor the COVID-19 situation

\footnotetext{
Address of Corresponding Author

Norbu Wangdi, Gongzim Ugyen Dorji Central School, Department of Physics Teaching, Haa, Bhutan.

$\triangle$ norbuwangdi5@education.gov.bt

0000-0002-5381-4724

How to cite: Wangdi, N., Dema, Y., \& Chogyel, N. (2021). Online learning amid COVID-19 pandemic: Perspectives of Bhutanese students. International Journal of Didactical Studies, 2(1), 101456. https://doi.org/10.33902/IJODS.2021167818
} 
within the country and beyond, we would like to keep our children home until we are confident about sending them to schools and colleges (Prime Minister's Office- PMO, Bhutan, 2020)

Prior to nation-wide lockdown in Bhutan, many countries all over the world has implemented online teaching and learning after the outbreak of coronavirus. In February 2020, China implemented an online learning to ensure that learning of students remain uninterrupted. Similarly, in April 2020, the Ministry of Education of Bulgaria has launched an e-learning system. In Finland, on account of school closures, instruction and guidance for students have been implemented by distance learning, digital learning environments and solutions (Rasmitadila, et al., 2020). Internet in Bhutan was introduced only in 1999 corresponding with silver jubilee celebration of His Majesty the great fourth Druk Gylapo. Since then the online classes in the form of email correspondence were introduced and practiced as a part of online classes in all the colleges under Royal University of Bhutan. Therefore, it was for the first time since Bhutan embraced the online teaching and learning after an inception of modern education in early 1960s.

Online teaching and learning involves the use of internet technologies and mobile applications, and it has transformed conventional classroom teaching style to the modern digital teaching system. As Asio and Riego de Dios (2019) mentioned that educators in the 21st century are expected to have a great deal of professional and personal qualities and extraordinary skills. Technology in education is not only beneficial for the students but also for teachers which creates the classroom environment more enjoyable. In addition, the advancement in educational technology has crossed the classroom boundaries and ensures the learning available all the time. Furthermore, educational technology enables the teachers to access the students at any time across boundaries and vice versa. In similar note, online learning also supports the students in attending the classes during their free time even they are at any other work (Elumalai, et al., 2020).

Bhutan had never experienced such a pandemic over the decades that has led to shut down of the schools across the country. Therefore, it has posed a significant challenge for both the teachers and students on practicing online classes. Similar challenges are being reported in neighboring countries like Pakistan. Lack of reliable and affordable internet connection has hindered the flow of online learning. In addition, significant amount of learning content is not accessible through the use smart phones (Adnan \& Anwar, 2020). The success of online learning is directly dependent on technological devices and internet, therefore, instructors and students with bad internet connections are liable to be denied access to online leaning (Adedoyin \& Soykan, 2020). However, with the directives and advice from Ministry of Education, the schools quickly conducted orientation for teachers and students on use of google classroom to ensure that teaching and learning takes place during the lockdown period.

The online teaching and learning took place through use of various innovative software and mobile applications such as google classroom, Facebook messenger, WeChat, Telegram, WhatsApp and Zoom. In addition, lessons for different classes were telecasted through BBS (National Television) initiated by the group of teachers from western districts of Bhutan. Due to worsening of pandemic situation, the schools for classes PP to VIII had remained closed for academic session 2020 and the assessments were also practiced through online platforms. However, for higher classes from IX to XII, schools were reopened from July and normal classroom teaching got resumed for a month. But unfortunately, schools got shut down once again in the month of August as the government imposed strict lockdown due to outbreak of corona cases in few of the southern districts.

The COVID-19 pandemic has forced Bhutanese education system to shift from conventional classroom setting to digital online teaching and learning. It has been almost a year since Bhutan has embraced online teaching and learning system to tackle the COVID situation. However, the feasibility to adopt digital online teaching and learning system in the least developed country like Bhutan remains a mystery. The same sentiment was reflected in the study of Asio and Bayucca (2020) where public schools were not yet ready to implement distance learning. A teacher from one of the remote districts argue that there is no proper internet connection in the school and not many students afford to buy smart phones, tablets or a computer lab top. Some teachers also questioned the capacity of parents to monitor the students' learning through online system (Rinzin, 2020). According to UNICEF Bhutan representative, Parks (2021) reported that parents had struggled to facilitate the learning of children especially the apresnts of younger children. The difficulties was felt particularly by both the parents who were office goers. Working single parents also struggled with home-based learning even more.

On account of the argument discussed above, the goal of the paper is to explore the perspectives of students towards online teaching and learning. Also, the paper highlights the 
perspectives of teachers and parents with regard to online learning through literature reviews. Therefore, the findings of this study can contribute towards enhancing the quality of online teaching and learning in the country if such pandemic arises in the near future as nothing is uncertain in this interconnected global community.

\subsection{Literature Review}

\subsubsection{Global perspectives towards online teaching and learning}

The closure of schools in China started in February 2020 following the increasing rate of coronavirus infection in Wuhan city. Very soon 120 countries closed the schools impacting billions of students across the world. On this note, COVID-19 pandemic has forced schools to adopt online learning to maintain teaching and learning alive even during the closure of schools (Guo et al., 2020; Shahzad et al., 2020). In United States the pandemic has claimed thousands of lives and leading to change the way hospitals, business centers, universities and school operates and functions (Wyse et al., 2020). Similarly in India, COVID-19 pandemic has led to closure of schools, universities and other educations institutes affecting the about 320 million of leaners across the country. The nationwide lockdown for months had badly affected students' learning progress (Jena, 2020; Petronzi \& Petronzi, 2020). In Brazil, Education sector was one of the first sector to suffer after the announcement of social distancing to reduce the spread of coronavirus (Spanemberg et al., 2020).

Numerous researchers came forward to carry out the impact of COVID-19 in educational setting across the world. For instance, Hasan and Khan, (2020) conducted study concerning to students' perspectives towards online teaching and learning. The findings of the study showed that students enjoyed online learning when proper facilities were accessible to them. However, poor network and connectivity has proven to be the major hindrances for students to cope up with online learning. The study involved 480 student participants from different universities of India. On similar note, (Coman et al., 2020) argue that teachers' lack of technical knowledge and rigidity towards adopting online learning environment has significant impact on students' learning. Adoption of online learning in Brazil was affected mainly due to inaccessibility of electronic equipment by the low income group people and poor quality of networks in remote parts of the country (Spanemberg et al., 2020). However, the researchers like Alqahtani and Rajkhan (2020) concluded that execution of online learning has played a significant role in boosting education process during COVID-19 pandemic. The data for the study was generated by interviewing $69 \mathrm{E}$ learning managers of different intuitions.

According to Hung Lau and Lee (2020), parents of Kindergarten schools in Hong Kong reported that some of the difficulties of online learning are; children's lack of concentration and interest, disruption from other family members, and the lack of resources and equipment. Teacher incompetency in designing interesting digital lesson also affected students' interest towards online learning. Furthermore, Nartiningrum and Nugroho (2020) investigated students' challenges of online amidst COVID-19 pandemic in Indonesian Education setting. The study found out that unstable net connectivity, lessened social interaction had resulted in poor learning and weakened commitment in learning. According to Surkhali and Garbuja (2020), Nepal has experienced both advantages and disadvantages from online learning amidst COVID-19 pandemic. Online learning has accelerated interaction between both teachers and students that has helped to maintain the teaching and learning on track. However, the flow of online learning was hindered by inaccessible electronic devices and expensive internet connection.

From the global perspectives, one of the factors that has led to deterioration of students' interest towards online learning is poor network connectivity and inaccessible of digital devices required to access online education (Asio \& Bayucca, 2020). Lack of parental support and disruption by the family members were also highlighted as other hindrances to the online learning. Furthermore, teachers' incompetency in digital knowledge and lack of skills in designing interesting online lessons also contributed towards declining students' interest in on learning. The literatures also pointed out that there is less interaction during online lessons as compared face to face classroom teaching which may potentially lead to minimal participation, distractions, withdrawal or complete disappearance of students. A lot of peer based learning, two-way communication and group discussion during online classes are not as fruitful as in actual face to face classroom teaching (Asio \& Bayucca, 2020).

\subsubsection{Bhutanese perspectives towards online teaching and learning}


The first-ever online teaching and learning in Bhutanese education system was embraced in the month of March, 2020 after the government announced to shut down the schools to combat the spread of coronavirus infection. Ministry of education had directed schools to continue teaching through online platforms so that students remain engaged at home during lockdown period. Although teachers of Bhutan welcomed the initiative of ministry of Education, some teachers also expressed some of the challenges associated with online teaching and learning. Students also highlighted that the high cost of internet, unreliable electricity supply and inaccessibility of electronic devices was some of the major challenges that posed serious obstructions to the flow of online learning.

According to Nima (2020), a teacher from Zhemgang pointed out that it is difficult to conduct online classes as most of the students do not access to digital devices like mobile phones, laptops etc. Therefore, she had decided to visit every houses in the community to ensure that students are learning at home. Most of the students were found engaged in farming activities with their parents there by students interest in learning is reduced. Another teacher expressed that many of his students were found looking after the cattle during the day and it was practically impossible for him to teach students through online classes. Due to closure of schools during pandemic, 210 students have dropped the school which is a significant number for small country like Bhutan. The overall strength of students is about 170 thousands as of 2020 . However some of the students are likely to return in 2021 academic year and continue their learning in the same classes (Drukpa, 2020).

One of the greatest challenge associated with online teaching and learning in Bhutan is unreliable and expensive internet charges. Due to high consumption of data, students hardly afford to attain online classes. Instead of spending the money to buy basic household necessities, it has to be spent on topping up the Internet data. Students hardly get time to attend online classes, as they are engaged in farming works with their old parents back at home. Students of remote places highlighted that the frequent disruption in the electricity supply in the villages has created inconvenient situation for them to attend online classes (Drukpa, 2020). In addition, Pokhrel and Chhetri (2021) pointed out that lack of parental guidance, especially for young learners, is another challenge, especially if both the parents were office goers. Students with special needs such visual and hearing impairment were affected the most.

As such there are only few literatures in context to Bhutanese online learning system, therefore, most of the literatures mentioned above are based on the newspapers articles. During the time of this study only few literatures were available in various online sources in context Bhutanese online learning. To derive some of the common problems associated with online teaching and learning in Bhutan are; expensive internet charges, inconsistent power supply in remote places and lack of parental support. Majority of the students were found involved in farming works and looking after the cattle.

\section{Method}

\subsection{Research Design}

This study applied mixed method to examine the perspectives of Gongzim students towards online teaching and learning in Bhutan. Both qualitative and quantitative approaches were employed in order to maximize the quality of the data. Since this research was intended to find out the students' perspectives towards online learning, both quantitative and qualitative data were employed to triangulate the data and solidify the findings. Doyle et al. (2009) identified eight benefits of using mixed methods. These eight benefits include: triangulation, completeness, offsetting weaknesses and providing stronger inferences, answering different research questions, explanation of findings, illustration of data, hypothesis development and testing, and instrument development and testing. Further, Creswell et al. (2004) claim that data triangulation design is one of the most prominent designs used by the researchers. The approach has been used as a means of triangulation in order for quantitative and qualitative data to help validate each other. The researchers collected both forms of data through the uses of google forms.

\subsection{Population and Sampling}

The target population for this study consisted of 600 student of Gongzim Ugyen Dorji Central School, Haa. This includes 350 boarder students and 250 day scholar students. Amongst 250 students, 100 were male and 100 female. However, boarder students was not included in the study due to lack of experience in online teaching and learning. Therefore, through purposive sampling, all the 250 day scholar students were selected as respondents. Both survey 
questionnaire and interview questions were dispensed through use of google forms, however only 200 responds were received while writing the analysis part of this study.

\subsection{Data Collection Methods and Instruments}

The data collection was administered through use of google forms. Researchers designed both interview questions and survey questionnaires using google forms and links were shared to students through Facebook messenger group, google classroom and WeChat. Both quantitative and qualitative data was collected through online during the nation-wide lock down in Bhutan.

\subsubsection{Survey}

A list of structured questions were designed using google forms and dispensed to the respondents to answer. The questionnaire was prepared based on the 5-point Likert-type scale of strongly agree, agree, neutral, disagree and strongly disagree. The preliminary survey questionnaire of this study was pilot tested through use of google forms. 30 students were included for the pilot study. The returned survey questionnaires were punched in SPSS for running reliability test. Reliability of the instruments was checked using Cronbach's Alpha. The Cronbach Alpha value received is 0.93. The high alpha reliability of both survey questionnaires leads to the conclusion that the survey designed for this study was a reliable.

\subsubsection{Survey}

Data collection for this study was carried out amid nationwide lockdown due to COVID-19 pandemic and therefore, researcher had dispensed interview questions along with the survey items using google form. The semi-structured questions were prepared to get the opinion of students regarding online learning. The number of response received was same as that of survey questionnaires.

\subsection{Data Analysis Procedure}

The quantitative data was analyzed using descriptive statistics. Similar statements were merged as a common theme and presented in the table. The response for each statement was interpreted in the form of percentage for easy understanding. An acronym for each of the 5-likert scale is used as follows; strongly agree (SA), agree (A), neutral (N), disagree (DA) and strongly disagree (SDA). But qualitative data was analyzed based on themes.

\section{Results}

This study was aimed to understand the perspectives of students towards online learning. Therefore, to procced with analyzation of data four major themes were identified from both qualitative and quantitative data to comprehend students' perspectives towards online learning. The themes are broadly classifies as; students attitude towards online learning, network issues, parents support and competency of teachers in online teaching.

Table 1

Students' attitude towards online learning

\begin{tabular}{lccccc}
\hline Statement & SA & A & N & DA & SDA \\
\hline $\begin{array}{l}\text { 1. I feel comfortable to use mobile } \\
\text { phone/laptops/tablet for online learning. }\end{array}$ & $13.4 \%$ & $41.5 \%$ & $28 \%$ & $12.2 \%$ & $4.9 \%$ \\
$\begin{array}{l}\text { 2. Online learning is more interesting than classroom } \\
\text { learning. }\end{array}$ & $1.2 \%$ & $9.8 \%$ & $22 \%$ & $37.8 \%$ & $29.3 \%$ \\
$\begin{array}{l}\text { 3. There is no difference between online learning and } \\
\text { actual classroom learning. }\end{array}$ & $3.7 \%$ & $6.1 \%$ & 9.8 & $58.5 \%$ & $22 \%$ \\
$\begin{array}{l}\text { 4. Face to face learning is more important than online } \\
\text { learning. }\end{array}$ & $50 \%$ & $39 \%$ & $7.3 \%$ & $2.4 \%$ & $2.4 \%$ \\
\hline
\end{tabular}

As illustrated in Table 1, students' attitude towards online learning is not that positive. Significant number of students feel that conventional classroom learning is effective compared online learning. This is evident from the rating against statements 2,3 and 4 . The statement 2 "Online learning is more interesting than classroom learning" received highest percentage in both disagree $(37.8 \%)$ and strongly disagree $(29.3 \%)$ category. Similarly, the percentage rating of both statement 3 and 4 suggest that, there is significant difference between online learning and face to 
face classroom learning. Meanwhile, the rating also suggest majority of the participants are competent in using mobile phones/laptops for education purpose.

The interview data concur with the findings of quantitative data. When students were asked about their satisfaction with online learning, majority of the students expressed that online learning and disorganized and inefficient compared to conventional learning. For instance one of the students mentioned; "I am not really satisfied because learning at classroom is more effective than learning online. We are not able to understand the topic well and unable to clear our doubt". Students also pointed out that, it is difficult to understand technical subject like mathematics and physics through online teaching. Few of the students even mentioned they get addicted to online games thereby reducing their interest in studies.

The rating of Table 2 indicates that students did not encountered with unreliable network and electricity supply during the online classes. This is clear from the percentage rating of statement number 1 and 3 . For instance, statement 3 "There is no reliable electricity supply in my place" received highest percentage in disagree $(54.9 \%)$ followed strongly disagree $(35.4 \%)$ category. However, significant number of students rated that internet charge is expensive in Bhutan as indicated in the percentage ratings of statement number 2 . The statement received $35.4 \%$ each for both agree and strongly agree category.

Table 2

Reliable and affordable internet for students

\begin{tabular}{|c|c|c|c|c|c|}
\hline Statements & SA & A & $\mathrm{N}$ & DA & SDA \\
\hline $\begin{array}{l}\text { in my place } \\
\text { e is expensive in }\end{array}$ & $17.1 \%$ & $23.2 \%$ & $23 \%$ & $24.4 \%$ & $12.2 \%$ \\
\hline & $35.4^{\circ}$ & $35.4 \%$ & & & $2.4 \%$ \\
\hline 3. There is no reliable electricity supply in my place. & $0 \%$ & $2.4 \%$ & $7.3 \%$ & $54.9 \%$ & $35.4 \%$ \\
\hline
\end{tabular}

It is interesting to note that the interview data closely agree with percentage ratings. Students pointed out that data consumption by both Bmobile and TashiCell is beyond their financial capacity. In Bhutan, Bmobile and TashiCell are the only two companies that provides cellular network services. Therefore, students from poor financial background face difficulty in attending online classes and thus they were left under emotional stress and demotivated to learn. One of the students states, "TashiCell and Mobile are consuming our data very fast. Last time, I watched 4 videos uploaded by my Mathematics teacher. In less than 30 minutes of time, all my 49 data got finished up. Therefore, I recommend government to look into this issue. If this trend continuous then I think many of us wouldn't able to attain the online classes".

According to the percentage rating shown in Table 3, it is understood that students received adequate support from the parents.

Table 3

Parents' support amid online classes

\begin{tabular}{lccccc}
\hline Statements & SA & A & N & DA & SDA \\
\hline $\begin{array}{l}\text { 1. I do not have my own personal phone. } \\
\begin{array}{l}\text { 2. I get maximum support from my parents while } \\
\text { learning online. }\end{array}\end{array}$ & $12.2 \%$ & $13.3 \%$ & $3.6 \%$ & $39.8 \%$ & $31.3 \%$ \\
$\begin{array}{l}\text { 3. I get less time to attend online classes due to } \\
\text { household works }\end{array}$ & $4 \%$ & $19.3 \%$ & $26.5 \%$ & $33.7 \%$ & $16.9 \%$
\end{tabular}

The statement number 2 "I get maximum support from my parents while learning online" received highest percentage in agree $(32.5 \%)$ and strongly agree $(22.9 \%)$ category. However, about $71 \%$ percent of the students do not have their own mobile phones/tablets/laptops as indicated by the rating against statement number 1 . Similarly, students' interview data also shows similar findings. Most of the students expressed that parents supported their online learning through buying data packages and relieving them from household chores and farming works. However, few students pointed out that they could not concentrate much on online learning because of disturbance from family members, television and neighbors.

The Table 4 describes the students' rating towards competency of teachers in delivery of online lessons. 
Table 4

Teachers competency in delivery of online lessons

\begin{tabular}{|c|c|c|c|c|c|}
\hline Statements & SA & $\mathrm{A}$ & $\mathrm{N}$ & $\mathrm{DA}$ & SDA \\
\hline 1. I find online lesson interesting and exciting. & $2.4 \%$ & $15.7 \%$ & $43.4 \%$ & $28.9 \%$ & $9.6 \%$ \\
\hline $\begin{array}{l}\text { 2. My teachers designs interesting online learning } \\
\text { materials }\end{array}$ & $4.8 \%$ & $31.3 \%$ & $49.4 \%$ & $8.4 \%$ & $6.0 \%$ \\
\hline $\begin{array}{l}\text { 3. I find my teachers incompetent to deliver lessons } \\
\text { through online. }\end{array}$ & $4.8 \%$ & $15.7 \%$ & $49.4 \%$ & $26.5 \%$ & $3.6 \%$ \\
\hline
\end{tabular}

The overall percentage received for the statements clearly indicates the incompetency of teachers in handling the online lesson. This applies that teachers were not able to design the online lessons that are interesting and exciting for students to learn. Many students had remained neutral and this indicate that they did not enjoy online lessons. The statement number 1 which describes "I find online lesson interesting and exciting" received $28.9 \%$ disagree and $9.8 \%$ strongly disagree. In case of interview data, students opted to remain neutral when asked about the competency of teachers in managing online classes which indicates that teachers are not skilled enough to design online lessons.

\section{Discussions}

This study was intended to explore the perspectives of Gongzim students towards online learning during closure of schools due to COVID-19 pandemic in the academic year 2020. It is interesting to note that students are not in favor of online learning as it is relatively ineffective as compared to conventional classroom learning. It is reported that students find difficult to understand online lessons especially the technical subjects like mathematics, chemistry and physics. This is possibly due to lack of human touch and absence of collaborative learning at home. Sinhal (2017) argue that technology will find hard to replace classroom teachers because it does not promote collaborative learning thereby depriving students from gaining social and organizational skills. The physical presence of a teacher promotes interactive learning that can excite stimulates students' leaning. In addition, a study conducted by Kaur et al. (2020) reported that online learning is inferior to classroom teaching, so students were not really satisfied with online learning.

Although, there isn't much issues with related to disruption of network and power supply, majority of the students highlighted the unaffordable cost of internet charges. Some of the students end up buying data package over the essential household items. The issue was also broadcasted by national television of Bhutan BBS (2019) which states that Bmobile users are using social media platforms and mainstream media as well to vent their frustrations over high data charges. In addition, similar story was reported by private newspaper the Bhutanese (Seldon, 2019). This finding also corroborates with Octaberlina and Muslimin (2020) who reported that students of Indonesia experienced three barriers during online learning which includes unfamiliarity of e-learning, slow internet connection and physical condition e.g. eye strain.

Majority of the students were found deprived of digital facilities like smart phones/laptops/tablets, however, it was found that parents supported students' online learning by allowing them to use their personal smart phones and exempting from everyday household chores. This finding closely concur with the findings of Bhamani et al. (2020). The study revealed that most of the mothers have been using Facebook and other social media to interact with teachers to keep their children engaged during lockdown period. Those familiar with technology and digital tools were involved in monitoring students learning and helping to complete assignments given by the teachers. According to Park (2021) UNICEF representative to Bhutan mentioned that due to closure of schools, there was overwhelming negative impact to the children in terms of both mental and physical wellbeing. These includes particularly for children of difficult families.

Teacher play an instrumental role in transforming traditional classroom teaching into online digital learning in such a desperate time when the education system around the world is collapsed due to wave of coronavirus. However, it is revealed that teachers failed to live up to the expectations of the students. Teachers were found incompetent in designing interesting lesson and make available online for students to learn. This finding corroborates with research which 
reported that teachers did not have appropriate digitals kills to manage online classes (Tejedor et al., 2020). Similarly Heng and Sol (2020) pointed out that the success of online learning depends entirely on technological devices, the internet and the user. So if teachers as primary users are not digitally competent due to inexperience or insufficient training, the success of online teaching remains questionable.

\section{Conclusion}

In Bhutan the colleges and the schools got closed for the first time in the mid of March 2020 and this has forced us to shift from conventional classroom learning to online digital learning despite numerous challenges that are likely to occur. The online learning has started right after the closure of schools for all levels of classes. However, the school was reopened for classes IX to XII from 1st July 2020, but had to close in August month due to nation-wide lockdown. However, for classes PP-VIII students, classes were managed through online for the whole academic year 2020. Therefore, this study was aimed to examine the perspectives of students towards online learning.

Findings of this study revealed that students has required knowledge to use digital devices like smart phones/laptops/tablets for educational purpose despite many of them do not have their own personal gadgets. Parents were also found to be equally concerned about children's' learning and supported them at the best of their capacity. The study also showed that students didn't face any problems with regard to mobile network connectivity and supply of electricity.

In addition, this study found out that the cost of internet is too expensive in Bhutan for students to attain online classes. Some of the students even sacrificed the buying of basic needs and went to purchase internet data packs. Another significant outcome of this study is that teachers are not really equipped with required skills and knowledge to manage online classes. Therefore, teachers failed to stimulate students' curiosity and interest to learn from online lessons.

\subsection{Limitations and Recommendations}

On account of the finding reported researchers recommend ministry of education to conduct workshop for teachers to enhance their digital skills and negotiate with cellular companies to reduce the internet cost in Bhutan. Also, ministry may try to provide tablet each for students to so that no students are left behind during such a desperate era. Nevertheless, this study has limitation as it was focused only in one urban school of Haa district, Bhutan. Future researchers may include participants from all parts of Bhutan through random sampling. This study may help to inform policy makers and educationist to provide better online education in such an unusual time.

Ethical Consideration. Researchers had obtained proper permission to carry out the study from relevant authorities and officials.

Acknowledgements. We would like to Thank Principal of Gongzim Ugyen Dorji for accepting our proposal to employ the students of Gongzim as particiapnts for this study. We would also like to thank all the students who had managed to participate in our data collection process despite their busy schedules.

\section{References}

Adedoyin, O. B \& Soykan, E. (2020). Covid-19 pandemic and online learning: The challenges and opportunities.
https: / / doi.org/ 10.1080/10494820.2020.1813180

Adnan. M., \& Anwar. K. (2020). Online learning amid the COVID-19 pandemic: Students' perspectives. Journal of Pedagogical Sociology and Psychology, 2(1), 45-51. http://www.doi.org/10.33902/JPSP.\%202020261309

Alqahtani, A. Y., \& Rajkhan, A. A. (2020). E-Learning critical success factors during the COVID-19 pandemic: A comprehensive analysis of E-Learning managerial perspectives. Education Sciences, 10, 2-16. http://dx.doi.org/10.3390/educsci10090216

Asio, J. M., \& Riego de Dios, E. (2019). The college students' perspective on what makes an educator well-qualified. Journal of Pedagogical Research, 3(3), 126-138. https://doi.org/jpr.v3i3.124

Asio, J.M.R. \& Bayucca, S.A (2020). Spearheading education during the COVID-19 rife: Administrators' level of digital competence and schools' readiness on distance learning. Journal 
of Pedagogical Sociology and Psychology, $\quad 3(1), \quad 19-26$.

https://doi.org/10.33902/JPSP.2021364728

BBS. (2019). BT and the question of data charges. Bhutan Broadcasting service. http://www.bbs.bt/news/?p=114182

Bhamani, S., Makhdoom, A. Z., Bharuchi, V., Ali, N., Kaleem, S., \& Ahmed, D. (2020). Home learning in times of COVID-19: Experiences. Journal of Education and Educational Development, 7(1), 09-26. http://dx.doi.org/10.22555/joeed.v7i1.3260

Coman, C., Țîru, L. G., Meseșan-Schmitz, L., Stanciu, C., \& Bularca, M. C. (2020). Online teaching and learning in higher education during the coronavirus Pandemic: Students' perspective. Sustainability, 12(24), 10367.

Creswell, J. W., Fetters, M. D., \& Ivankova, N. V. (2004). Designing a mixed method study in primary care. The Annals of Family Medicine, 2(1), 7-12.

Doyle, L., Brady, A. M., \& Byrne, G. (2009). An overview of mixed methods research. Journal of Research in Nursing, 14(2), 175-185.

Drukpa, U. (2020, April 11). Students adjust to online learning and its Challenges. The Bhutanese. https://thebhutanese.bt/students-adjust-to-online-learning-and-its- challenges/

Drukpa, U. (2020, August 8). Most Class X and XII dropped out students to continue studies in 2021: MoE. The Bhutanese. https://thebhutanese.bt/most-class-x-and-xii-dropped-outstudents-to-continue-studies-in-2021-moe/

Elumalai, K. V., Sankar, J. P., R, K., John, J. A., Menon, N., Alqahtani, M. S. N., \& Abumelha. M. A. (2020). Factors affecting the quality of e-learning during the COVID-19 pandemic from the perspective of higher education students. Journal of Information Technology Education, Research, 19, 731-753. https://doi.org/10.28945/4628

Guo, J., Huang, F., Lou, Y., \& Chen, S. (2020). Students' perceptions of using mobile technologies in informal English learning during the COVID-19 epidemic: A study in Chinese rural secondary schools. Journal of Pedagogical Research, 4(4), 475-483.

Hasan, N., \& Khan, N. H. (2020). Online teaching-learning during COVID-19 pandemic: students' perspectives. The Online Journal of Distance Education and e-Learning, 8(4), 202-213.

Heng, K., \& Sol, K. (2020, December 08). Online learning during COVID-19: Key challenges and suggestions to enhance effectiveness. Cambodian Education Forum .https:/ / cambodianeducationforum.wordpress.com/2020/12/08/onlinelearning-during-covid19-key-challenges-and-suggestions-to-enhanceeffectiveness /

Hung Lau, E. Y., \& Lee, K. (2020). Parents' views on young children's distance learning and screen time during COVID-19 class Suspension in Hong Kong. Early Education and Development. https://doi.org/10.1080/10409289.2020.1843925

Jena, P. K. (2020). Impact of Pandemic COVID-19 on Education in India. International Journal of Current Research, 12(11), 12582-12586. http://journalcra.com/article/impact-pandemiccovid-19-education-india

Kado, K., Dem, N., \& Yonten S. (2020). Effectiveness of Google classroom as an online learning management system in the wake of COVID-19 in Bhutan: Students'perceptions. In I. Sahin \& M. Shelley (Eds.), Educational practices during the during the COVID-19 viral outbreak: International perspectives (pp. 121-142). ISTES Organization.

Kaur, N., Dwivedi, D., Arora, J., \& Gandhi, A. (2020). Study of the effectiveness of e- learning to conventional teaching in medical undergraduates amid COVID-19 pandemic. National Journal of Physiology, Pharmacy and Pharmacology, 10(7), 1-5. https://doi.org/10.5455/njppp.2020.10.04096202028042020

Nartiningrum, N., \& Nugroho, A. (2020). Online learning amidst global pandemic: EFL students' challenges, suggestions, and needed materials. Academic Journal of English Language and Education, 4(2), 115-140. http://dx.doi.org/10.29240/ef.v4i2.1494

Nima, (2020, June 12). E-learning challenges in Zhemgang. Kuensel. https://kuenselonline.com/e-learning-challenges-in-zhemgang/

Octaberlina, R. L., \& Muslimin, L. A. (2020). EFL Students perspective towards online learning barriers and alternatives using Moodle/Google classroom during COVID-19 pandemic. International Journal of Higher Education, 9(6), 1-9. https://doi.org/10.5430/ijhe.v9n6p1

Parks, W. (2021). The impact of school closure on children. https://www.unicef.org/bhutan/impact-school-closure-children

Petronzi, R., \& Petronzi, D. (2020). The Online and Campus (OaC) model as a sustainable blended approach to teaching and learning in higher education: A response to COVID-19. Journal of Pedagogical Research, 4(4), 498-507. https://doi.org/10.33902/JPR.2020064475 
Pokhre1, S. \& Chhetri, S. (2021). A Literature Review on Impact of COVID-19 Pandemic on Teaching and Learning. Higher Education for the Future, 8(1), 133-141. https://doi.org/10.1177/2347631120983481

Prime Minister's Office- PMO, Bhutan. (2020, March 17). All schools and educational institutes across the country will remain closed starting tomorrow (March 18), until further order from the government. https://www.facebook.com/PMOBhutan/posts/update-all-schools-andeducational-institutes-across-

Rasmitadila, R., Aliyyah, R. R., Rachmadtullah, R., Samsudin, A., Syaodih, E., Nurtanto, M., \& Tambunan, A. R. S. (2020). Perceptions of primary school teachers of online learning during the COVID-19 pandemic period: A case study in Indonesia. Journal of Ethnic and Cultural Studies, 7(2), 90-109. http://dx.doi.org/10.29333/ejecs/388

Rinzin, Y. C. (2020, March 21). E-learning explored to engage students. Kuensel. https://kuenselonline.com/e-learning-explored-to-engage-students

Seldon, P. (2019, May 25). No overcharging on data usage by BT says MoEA minister. The Bhutanese. https://thebhutanese.bt/no-overcharging-on-data-usage-by-bt-says-moea- minister/

Shahzad, A., Hassan, R., Aremu, A. Y., Hussan, A. \& Lodhi, R. N. (2020). Effects of COVID-19 in e-learning on higher education institution students: The group comparison between male and female. Quality \& Quantity. https://doi.org/10.1007/s11135-020-01028-z

Sinhal, S. (2017, June 23). 7 ways classroom teaching is better than online education. India Today. https://www.indiatoday.in/education-today/featurephilia/story/classroom-teaching-better-than-onlineeducation-984387-2017-06-23

Spanemberg, J. C., Simões, C. C., \& Cardoso, J. A. (2020). The impacts of the COVID-19 pandemic on the teaching of dentistry in Brazil. Journal of Dental Education, 84(11), 11851187.

Surkhali B, \& Garbuja C. K. (2020). Virtual learning during COVID-19 pandemic: Pros and cons. Journal of Lumbini Medical College, 8(1). https://doi.org/10.22502/jlmc.v8i1.3

Tejedor, S., Cervi, L., Pérez-Escoda, A., \& Jumbo, F. T. (2020). Digital literacy and higher education during COVID-19 lockdown: Spain, Italy, and Ecuador. Publications, 8(4), 48. http://dx.doi.org/10.3390/publications8040048

United Nations [UN]. (2020). Policy brief: Education during COVID-19 and beyond. United Nations.

Wyse, A. E., Stickney, E. M., Butz, D., Beckler, A., \& Close, C. N. (2020). The potential impact of COVID-19 on student learning and how schools can respond. Educational Measurement: Issues and Practice, 39(3), 60-64. 